\title{
Shape and Orifice Optimization of Airbag Systems for UAV Parachute Landing
}

\author{
Masoud Alizadeh* \\ Department of Aerospace Engineering, Sharif University of Technology, Tehran 11365-11155, Iran
}

\author{
Ahmad Sedaghat** \\ Department of Mechanical Engineering, Isfahan University of Technology, Isfahan 84156-83111, Iran \\ Ebrahim Kargar*** \\ Department of Aerospace Engineering, Malek Ashtar University of Technology, Isfahan 15875-1774, Iran
}

\begin{abstract}
An airbag is an important safety system and is well known as a safety system in cars during an accident. Airbag systems are also used as a shock absorber for UAVs to assist with rapid parachute landings. In this paper, the dynamics and gas dynamics of five airbag shapes, cylindrical, semi-cylindrical, cubic, and two truncated pyramids, were modelled and simulated under conditions of impact acceleration lower than $4 \mathrm{~m} / \mathrm{s}^{2}$ to avoid damage to the UAV. First, the responses of the present modelling were compared and validated against airbag test results under the same conditions. Second, for each airbag shape under the same conditions, the responses in terms of pressure, acceleration, and emerging velocity were investigated. Third, the performance of a pressure relief valve is compared with a fixed-area orifice implemented in the air bag. For each airbag shape under the same conditions, the optimum area of the fixed orifice was determined. By examining the response of pressure and acceleration of the airbag, the optimum shape of the airbag and the venting system is suggested.
\end{abstract}

Key words: Airbag, Gas dynamics, Shock absorber, UAV, Venting system

\section{Introduction}

Airbag systems have been used widely in different applications such as in cars or as shock absorbers in cargo landings. Such systems have also been used to protect astronauts landing and rapid parachute jumpers in topologically difficult fields. The airbag is often combined with a parachute system. In the landing process, first, the parachute system is used to reduce the velocity to $\sim 5$ to $10 \mathrm{~m} / \mathrm{s}$. Then, an airbag system is activated on touchdown to absorb the kinetic energy, as a shock absorber, during the impact with the ground. An important task is the selection of the design parameters for the airbag system to protects humans, with specific impact velocities in mind. Three parameters are usually selected as input variables. These are the airbag volume, airbag height, and orifice area. In this paper, the simultaneous optimisation of five major outputs is sought: the airbag internal pressure response, the deceleration level of the attached landing platform of the payload, the vertical velocity, the orifice flow rate, and the displacement of the airbag.

The testing of airbags can be both expensive and time consuming. Using computer modelling and simulations, airbag specifications, such as the airbag height and orifice size,
This is an Open Access article distributed under the terms of the Creative Commons Attribution Non-Commercial License (http://creativecommons.org/licenses/by$\mathrm{nc} / 3.0 /$ which permits unrestricted non-commercial use, distribution, and reproduction in any medium, provided the original work is properly cited. (c) Master Student
** Associate Professor, Corresponding Author : sedaghat@cc.iut.ac.ir
*** Master Student 
can be determined and the resulting number of experiments and costs can be reduced significantly.

Some theoretical approach developed by Browntng [1] have dealt with the airbag internal pressure response, the mass rates of flow into and out of the airbag, shape functions, the deceleration level of the attached landing platforms payload, and the vertical velocity and displacement of the airbag. Rosato [2] studied the dynamic behaviour of the airbag vent and its control experimentally.

In other analytical studies on cylindrical airbags, shape functions were assumed such that the axial length of cylindrical airbags remained constant throughout the compression process [4]. As a result, these functions only focus on the changing cross section of the airbag from its initial circular shape. Semi-cylindrical and truncated pyramid airbags were modelled similarly to the cylindrical airbags, using shape functions.

The European Space Research and Technology Centre [5] have modelled the entire descent and landing phase, from the end of the entry phase, through the deployment of parachutes, the activation of propulsive velocity control systems, and finally the landing with a vented airbag system.

In selecting airbag materials, the deployment method dictates all aspects of the system. However, despite various considerations and the use of different materials for the airbag, nylon 6.6 remains the material of choice [6].

Analysis of airbag deployment has become a routine requirement in restraint-system design. With LS-DYNA's software capabilities for modelling the gas flow, the research has come to place increased emphasis on modelling the fold pattern accurately, and consequently the requirement to analyse many different candidate fold patterns [9].

Computational studies by Ross [11] who investigated control laws to be used to optimize airbag platform landings involved conceptually simulated open-loop and feedback controller designs. Another prior digital computer model developed by Lai [12] established guidelines for the application of airbags as alternative energy dissipaters to soft-land parachute-delivered loads.

In this paper, the modelling of gas dynamics and the dynamics of airbags are explained in Section 2 for cylindrical, semi-cylindrical, and truncated pyramid shapes. Simulations of airbag models are provided in Section 3 and compared with some available experimental data. Results of the models using a fixed-area orifice and an orifice with a pressure relief valve are also presented in Section 3 and optimum solutions are suggested. In Section 4 , our conclusions are provided regarding the application of airbags for UAV safe landing.

\section{Airbag modelling}

In this paper, five airbags of different shapes are considered. In the first step, gas dynamics and dynamic equations are presented. The gas flow is modelled using the mass flow rate from the orifice. The assumptions are that the airbag cross sectional shape and the vent area remain constant during impact. The continuity equation is given for the airbag system as [1]:

$$
\frac{\mathrm{dM}}{\mathrm{dt}_{\mathrm{sys}}}=\frac{\partial \mathrm{M}}{\partial \mathrm{t}_{\mathrm{c} . \mathrm{v}}}+\int_{\mathrm{c} . \mathrm{v}} \rho \mathrm{V}_{\mathrm{n}} \mathrm{dA}=0
$$

which can be simplified to [1]:

$$
-\frac{d\left(\rho_{\text {bag }} h B\right)}{d t}=\rho_{\text {or }} a_{\text {or }} C_{D}
$$

where $\rho$ is the air density, $\mathrm{h}$ and B are the height and crosssection of the airbag, $\mathrm{q}_{\text {or }}$ is the flow velocity through the orifice, and $C_{D}$ is the discharge coefficient given by [1]:

$$
\mathrm{C}_{\mathrm{D}}=0.9-\frac{0.3}{\left(\frac{\mathrm{P}_{\mathrm{bag}}}{\mathrm{P}_{\mathrm{a}}}\right)}
$$

The bag compression usually takes about $0.2 \mathrm{~s}$ to occur, so the adiabatic relationship holds to determine air density:

$$
\rho_{\text {bag }}=\rho_{\mathrm{a}}\left(\frac{\mathrm{P}_{\mathrm{bag}}}{\mathrm{P}_{\mathrm{a}}}\right)^{\frac{1}{\gamma}}
$$

Here, $\mathrm{P}_{\mathrm{a}}$ is the initial (atmospheric) pressure. The orifice flow equation, after some manipulation expressed in [1], is given as:

$$
\frac{\mathrm{dP}}{\mathrm{dt}}=-\frac{\frac{\mathrm{aC}_{\mathrm{D}}}{\mathrm{B}} \sqrt{\frac{2 \gamma}{\gamma-1}\left(\frac{\mathrm{c}^{2}}{\gamma}\right)\left((\mathrm{P})^{1-\frac{1}{\gamma}}-1\right)}+\frac{\mathrm{dx}}{\mathrm{dt}}(\mathrm{p})^{\frac{1}{\gamma}}}{\frac{\mathrm{h}}{\gamma}(\mathrm{p})^{\frac{1}{\gamma}-1}}
$$

With a choked orifice, the flow velocity $q$ is always equal to the speed of sound and the pressure at the orifice is greater than atmospheric, the ratio of bag pressure to orifice pressure being fixed at 1.894. That means when the bag pressure reach $75.36 \mathrm{kPa}$ (at sea level), the flow expands to supersonic speed outside the bag but soon breaks down to subsonic speed due to shock waves. The airbag maximum pressure does not reach this amount. Hence, the choked orifice has not been investigated.

Thus, the system dynamics equation, using Newton's second law of motion, according to Fig. 1, becomes: 


$$
-\mathrm{Mg}+\left(\mathrm{P}_{\mathrm{bag}}-\mathrm{P}_{\mathrm{a}}\right) \mathrm{B}(h)=\mathrm{M} \frac{\mathrm{d}^{2} \mathrm{~h}}{\mathrm{dt}^{2}}
$$

In this equation, it is assumed that $\mathrm{B}(\mathrm{h})$ is a constant value.

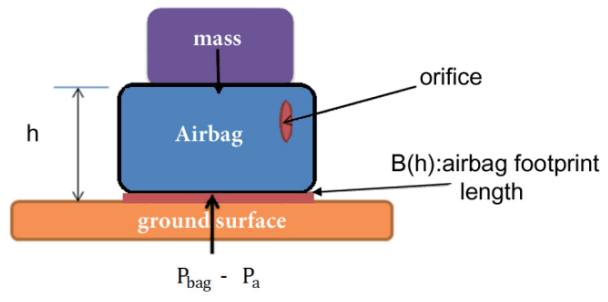

Fig. 1. Impact modelling for the cubic airbags

By simultaneously solving Equations (5) and (6) with respect to time, the airbag output characteristics are obtained.

\subsection{Cylindrical and semi-cylindrical airbag modelling}

Cylindrical airbags are a conventional airbag type. An analytical study performed in 1960 revealed that the shape functions assume the axial length of a cylindrical airbag remains constant throughout the compression process. As a result, these functions only focus on the changing crosssection of the airbag from its initial circular shape, as shown in Fig. 2 [3].

Here, a condition is enforced such that the circumference of the airbag cross-section remains constant throughout. In effect, this is equivalent to conservation of the airbag surface area value. Thus, in terms of the framework presented in Fig. 2 , this can be expressed as [3]:

$$
\pi \mathrm{D}=\pi \mathrm{h}+2 \mathrm{l}_{\mathrm{f} . \mathrm{p}}
$$

Rearranging Equation (7) yields a relationship for the airbag footprint length as a function of the airbag stroke [3]:

$$
1_{\text {f.p }}=\frac{\pi(D-h)}{2}
$$

With this, the cross-sectional area of the airbag in the stroked state can be determined using the fact that it consists
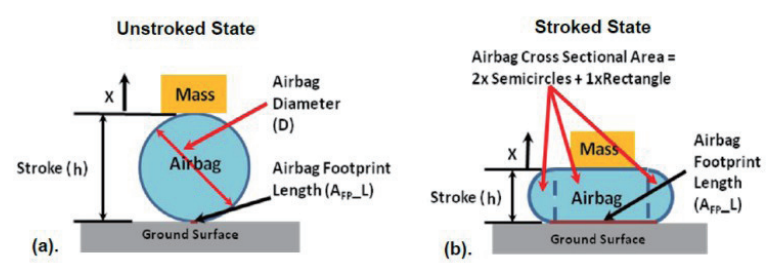

Fig. 2. Shape function used in airbag impact model; (a) the unstroked state, (b) the stroked state [3]. of a rectangle and two semi-circles, as depicted in Fig. 2(b). Thus:

$$
\mathrm{A}_{\mathrm{sec}}=\frac{\pi(\mathrm{Dh})}{2}-\frac{\pi(\mathrm{h})^{2}}{4}
$$

Differentiating with time:

$$
\mathrm{A}_{\mathrm{sec}}^{\prime}=1_{\mathrm{f} . \mathrm{p}} \frac{\mathrm{dh}}{\mathrm{dt}}
$$

For a semi-cylindrical airbag with same method, the cross-sectional area of the airbag in the stroked state can be determined using the fact that it consists of a rectangle and two quadrants (as in Fig. 2). $1_{\text {f.p }}, A_{\text {sec }}$ and $A_{\text {sec }}^{\prime}$ can be expressed as:

$$
\begin{aligned}
& \mathrm{l}_{\text {f.p }}=(\mathrm{R}-\mathrm{h})\left(1+\frac{\pi}{2}\right) \\
& \mathrm{A}_{\mathrm{sec}}=(\mathrm{R} \mathrm{h})\left(1+\frac{\pi}{2}\right)-\mathrm{h}^{2} \\
& \mathrm{~A}_{\mathrm{sec}}^{\prime}=\left(\mathrm{R}\left(1+\frac{\pi}{2}\right)-2 \mathrm{~h}\right) \frac{\mathrm{dh}}{\mathrm{dt}}
\end{aligned}
$$

Thus, the orifice flow equation, for semi-cylindrical and cylindrical airbags becomes:

$$
\frac{\mathrm{dP}}{\mathrm{dt}}=-\frac{\frac{\mathrm{aC}_{\mathrm{D}}}{1} \sqrt{\frac{2 \gamma}{\gamma-1}\left(\frac{\mathrm{c}^{2}}{\gamma}\right)\left((\mathrm{P})^{1-\frac{1}{\gamma}}-1\right)}}{\frac{\mathrm{A}_{\mathrm{sec}}}{\gamma}(\mathrm{p})^{\frac{1}{\gamma}-1}}+\frac{(\mathrm{p})^{\frac{1}{\gamma}} \mathrm{A}_{\mathrm{sec}}^{\prime}}{\frac{\mathrm{A}_{\mathrm{sec}}}{\gamma}(\mathrm{p})^{\frac{1}{\gamma}-1}}
$$

where $\frac{\mathrm{P}_{\mathrm{bag}}}{\mathrm{P}_{\mathrm{a}}}=P$, as in equation (5). In this equation $\mathrm{B}(\mathrm{h})$ is not constant and changes with airbag height changes. For semi-cylindrical and cylindrical airbags, $\mathrm{B}(\mathrm{h})$ is obtained from:

$$
\mathrm{B}(\mathrm{h})=\mathrm{l}_{\text {f.p }} 1
$$

Simultaneously, by solving Equations (6) and (14) with respect to time, the semi-cylindrical and cylindrical airbags output characteristics are obtained.

\subsection{Truncated pyramid airbag modelling}

Truncated pyramid airbags are another conventional type of airbag, as shown in Fig. 3. One of the design parameters in the truncated pyramid airbag is the ratio of $B_{1}$ to $B_{2}$. To express this aspect, three states are considered:

$$
\begin{aligned}
& \text { 1. } \mathrm{B}_{1}=1.5 \mathrm{~B}_{2} \\
& \text { 2. } \mathrm{B}_{2}=1.5 \mathrm{~B}_{1}
\end{aligned}
$$




$$
\text { 3. } \mathrm{B}_{1}=\mathrm{B}_{2}
$$

In these airbag types, it is assumed that the airbag footprint area changes from $B_{1}$ to $B_{2}$ throughout the compression process. That is, footprint area at any time is constant, but, the footprint area starts from $B_{1}$ and increases (or decreases for an inverse type) to $\mathrm{B}_{2}$.

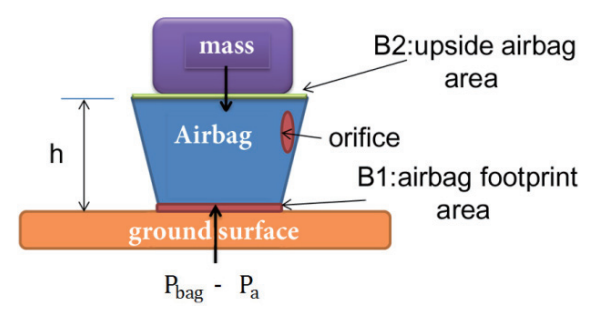

Fig. 3. Impact modelling for truncated pyramid airbags

The continuity equation for this airbag, i.e., equation (2), becomes:

$$
-\frac{d\left(\rho_{\text {bag }} h \bar{B}\right)}{d t}=\rho_{\text {or }} a q_{o r} C_{D}
$$

where:

$$
\overline{\mathrm{B}}=\frac{\mathrm{B}_{2}+\left(\mathrm{B}_{2}-\left(\frac{\mathrm{B}_{2}-\mathrm{B}_{1}}{\mathrm{~h}_{0}}\right) \mathrm{h}\right)}{2}
$$

Thus, the orifice flow equation, for the truncated pyramid airbags is derived as:

$$
\frac{\mathrm{dP}}{\mathrm{dt}}=-\frac{\mathrm{aC}_{\mathrm{D}} \sqrt{\frac{2 \gamma}{\gamma-1}\left(\frac{\mathrm{c}^{2}}{\gamma}\right)\left((\mathrm{P})^{1-\frac{1}{\gamma}}-1\right)}}{\overline{\mathrm{B}} \frac{\mathrm{h}}{\gamma}(\mathrm{p})^{\frac{1}{\gamma}-1}}+\frac{(\mathrm{p})^{\frac{1}{\gamma}} \frac{\mathrm{dh}}{\mathrm{dt}}\left(\mathrm{B}_{2}-\left(\left(\frac{\mathrm{B}_{2}-\mathrm{B}_{1}}{\mathrm{~h}_{0}}\right) \mathrm{h}\right)\right)}{\overline{\mathrm{B}} \frac{\mathrm{h}}{\gamma}(\mathrm{p})^{\frac{1}{\gamma}-1}}
$$

In this case, $\mathrm{B}(\mathrm{h})$ is not constant and changes with airbag height. For truncated pyramid airbags $B(h)$ is obtained from:

$$
\mathrm{B}(\mathrm{h})=\left(\mathrm{B}_{2}-\left(\frac{\mathrm{B}_{2}-\mathrm{B}_{1}}{\mathrm{~h}_{0}}\right) \mathrm{h}\right)
$$

Simultaneously solving Equations (6) and (18) with respect to time, the truncated pyramid airbags output characteristics are determined.

\section{Results and Discussion}

\subsection{Validation of a rectangular airbag model}

Computational studies by Ross [11], who investigated control laws to be used to optimize airbag platform landings, involved conceptually simulated open-loop as well as feedback-controller designs. Another prior model, developed by Lai [12], established guidelines for the application of airbags as alternative energy dissipaters to soft-land parachute-delivered loads. The Lai model explored the improvement in efficiency achieved through added mass gas-injection into the airbag [2].

To validate current model, an exercise was undertaken to compare its performance with previously published analytical results. The model was simulated to produce a 21 $\mathrm{ft} / \mathrm{s}$ impact of a simple $(8 \mathrm{ft} \times 4 \mathrm{ft} \times 4 \mathrm{ft})$ rectangular (cube) airbag supporting a $1390 \mathrm{lb}$ payload with an area of $1.39 \mathrm{ft}^{2}$ for the fixed open orifice. This case was previously reported by Rosato and Ross [2].

Results of the current model, Ross and Rosato are compared in Fig. 4. This response appears to be a 'smoother' version of Lai's results and it is the same as Ross and Rosato's results. The shape and magnitude of the airbag pressure response appears to be the same. Thus, in the next section, five airbags with different shapes are presented for optimization purposes.

\subsection{Results of the different simulated airbags shapes}

In this paper, the airbags considered support a $150(\mathrm{~kg})$ UAV with an impact velocity of $7 \mathrm{~m} / \mathrm{s}$ with the airbag cross section area of $0.4\left(\mathrm{~m}^{2}\right)$ and height of $0.85(\mathrm{~m})$. Results are presented in the following three sub-sections. In section 3.2.1, for a constant orifice area, the performances of five airbag types are investigated. Section 3.2.2 discusses pressure relief valve performance and in section 3.2 .3 , the effects of a pressure relief valve on these five airbag types is investigated and the orifice area is optimized.

\subsubsection{Fixed area orifice optimization}

In this section, the optimum fixed orifice area $0.018\left(\mathrm{~m}^{2}\right)$ is

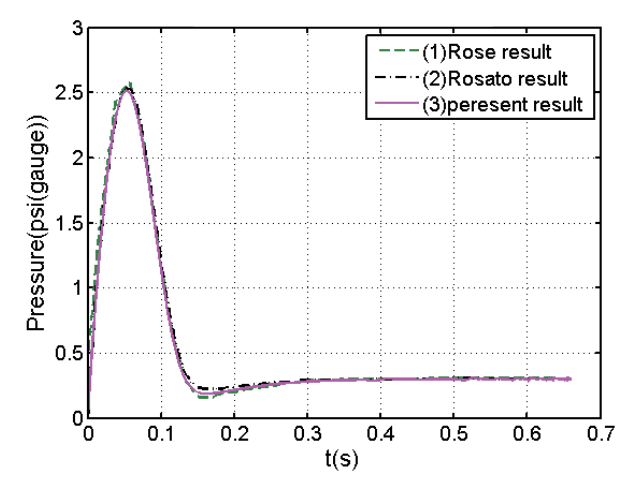

Fig. 4. Validation of pressure response with the developed digital computer model compared with the results of Rosato and Ross [2]. 
obtained. Five airbags with different shapes were modelled. Specifications of these airbags are given in Table 1. According to Table 1, each airbag is allocated one number, which is referred to in the legends of Fig. 5 to Fig. 8.

For each airbag type under the same conditions, the responses of pressure, acceleration, end process velocity, and airbag height for these shapes are shown in Fig. 5-8. Fig. 5 and 6 show that the maximum internal pressure and payload acceleration can be produced by semi-cylindrical and cylindrical airbags in comparison with other airbags. Also, the location of the maximum acceleration and the maximum pressure response is delayed.

The maximum magnitude of acceleration and airbag pressure in semi-cylindrical airbags is larger than with cylindrical airbags, but according to Fig. 3, end-process velocity in semi-cylindrical airbags is smaller than in cylindrical airbags. Also, the maximum magnitude of acceleration in both bags is larger than truncated pyramid airbags, but according to Fig. 3, the end-process velocity in these airbags is smaller than in the truncated pyramid airbags. These airbags could reduce speed to $\sim 1 \mathrm{~m} / \mathrm{s}$. However, truncated pyramid airbags under the same conditions cannot reduce velocity to $\sim 1 \mathrm{~m} / \mathrm{s}$ without bouncing back. In the landing process, bouncing back can lead to overturning, which is unacceptable in airbag design.

In truncated pyramid airbags, case 1 has better performance in comparison with cases 2 and 3 . As can be seen in Fig. 5 to 7 while case 1 has less maximum acceleration and pressure, the end process velocity is unchanged. Because when the velocity is at maximum magnitude, the airbag volume changing at a minimum value and at the end of impact, when the velocity reaches a minimum, airbag volume changes reach a maximum; thus, the maximum pressure and acceleration magnitude are reduced.

According to Fig. 8, because bouncing back occurs, with the fixed-area orifice airbags of about $20 \%$, the addition of airbag height is useless.

\subsubsection{Pressure relief valve effect}

In this section, the effect on airbag performance of using a pressure relief valve, instead of a fixed area orifice,

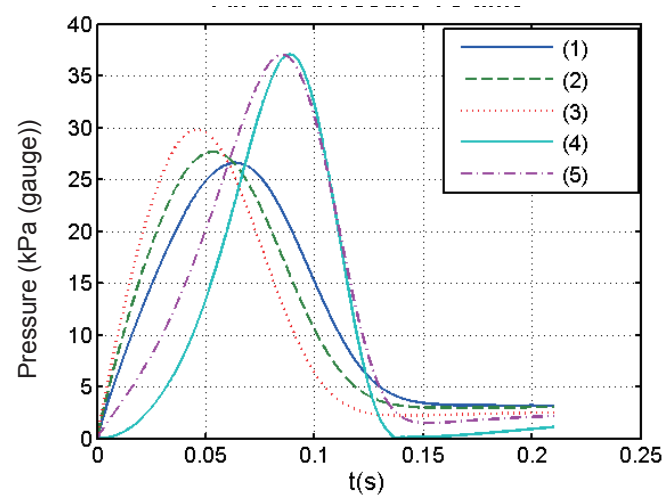

Fig. 5. Pressure response of five airbags in Table 1 with fixed orifice area.

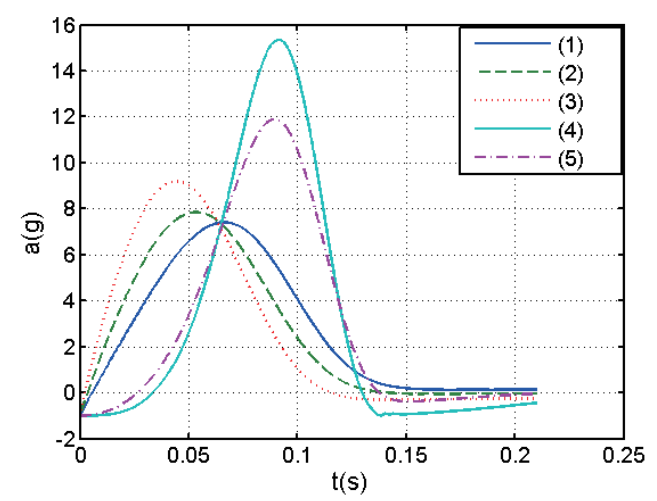

Fig. 6. Acceleration response of five airbags in Table 1 with fixed orifice area.

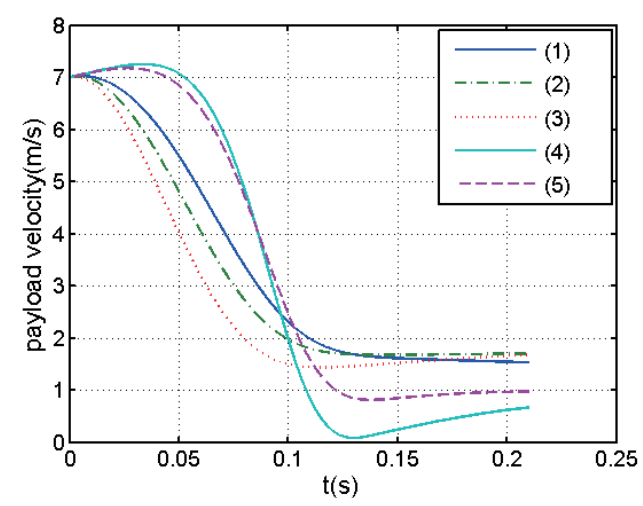

Fig. 7. Velocity response of five airbags in Table 1 with fixed orifice area.

Table 1. Specifications of the five airbags with different shapes

\begin{tabular}{ccc}
\hline $\begin{array}{c}\text { Case number } \\
\text { (Airbag Identifier) }\end{array}$ & Airbag type & $\begin{array}{c}\text { Fixed orifice area } \\
\left(\mathrm{m}^{2}\right)\end{array}$ \\
\hline 1 & Truncated pyramid with top area=1.5 & 0.018 \\
2 & Cubic & 0.018 \\
3 & Truncated pyramid with bottom area $=1.5 \times$ upside area & 0.018 \\
4 & Cylindrical with $\mathrm{D}=\mathrm{h}$ airbag & 0.018 \\
5 & Semi cylindrical with $\mathrm{R}=\mathrm{h}$ airbag & 0.018 \\
\hline
\end{tabular}




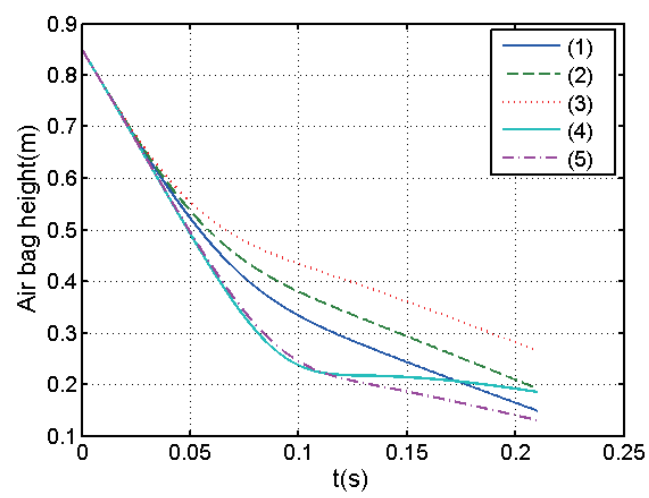

Fig. 8. Airbag height response of five airbags in Table 1 with fixed orifice area.

is investigated. The pressure relief valve, shown in Fig. 9, is closed at the primary time of impact process. When the internal airbag pressure is increased to $\mathrm{P}_{\text {set }}{ }^{4}$, orifice area is increased linearly to $\left(\mathrm{A}_{\text {or max }}^{5}\right)$; afterwards, with increasing pressure, the orifice area does not change. Thus, for analysing this orifice type, there are three parameters:

\section{1. $\mathrm{P}_{\text {set }}$ \\ 2. Ks \\ 3. $A_{\text {or max }}$}

$\mathrm{A}_{\text {ormax }}$ and $\mathrm{P}_{\text {set }}$ are described. Ks is the spring rate deflection. According to Fig. 9, in this type of pressure relief valve, a torsional spring is used. In this paper, it has been assumed that $\mathrm{Ks}=0.1$ (N.m/deg) and, for each case, $\mathrm{A}_{\text {or max }}$ and $\mathrm{P}_{\text {set }}$ are obtained by direct search.

As shown in Fig. 14, when a pressure relief valve is used, $A_{\text {or max }}$ can be increased until the maximum required orifice area becomes constant. Then, $\mathrm{P}_{\text {set }}$ must be chosen so that the velocity reaches $0 \mathrm{~m} / \mathrm{s}$.

To study the pressure relief valve effect, case 1 in Table 1 was chosen. We sought to optimize its performance by using a pressure relief valve instead of a fixed area orifice. By trial and error $\mathrm{A}_{\text {or } \max }=0.025 \mathrm{~m}^{2}$ and $\mathrm{P}_{\text {set }}=5.5 \mathrm{kPa}$ for this case. For comparison, a new case was created by changing the fixed

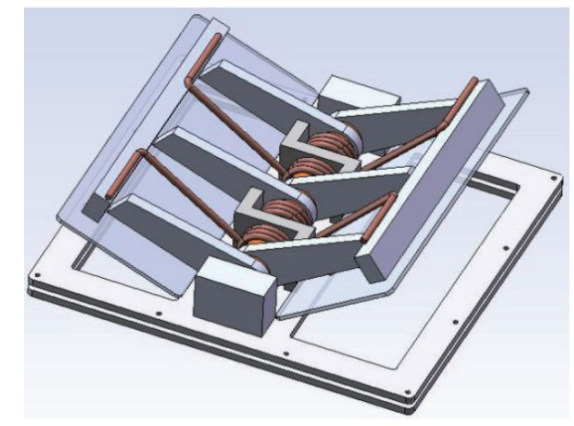

Fig. 9. A type of pressure relief valve used in the airbags [3] orifice area of case 1 from $0.018 \mathrm{~m}^{2}$ to $0.025 \mathrm{~m}^{2}$, equal to $\mathrm{A}_{\text {or } \max }$ become spited. As seen in Fig. 10 and 11, using a pressure relief valve, the maximum pressure and acceleration were reduced, and the end process velocity (according to Fig. 12) was reduced to $0 \mathrm{~m} / \mathrm{s}$ with no bouncing back.

As seen in Fig. 10, the pressure relief valve caused a decrease in the maximum pressure, but the pressure diagram has a lower slope when the pressure is decreasing.

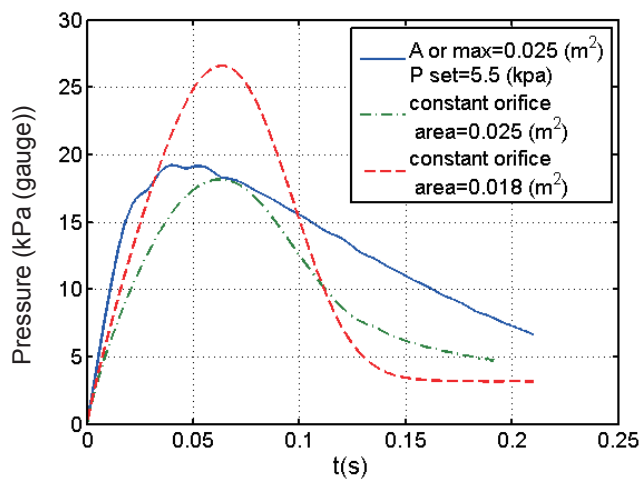

Fig. 10. Pressure response to compression fixed area orifice with pressure relief valve performance in airbag.

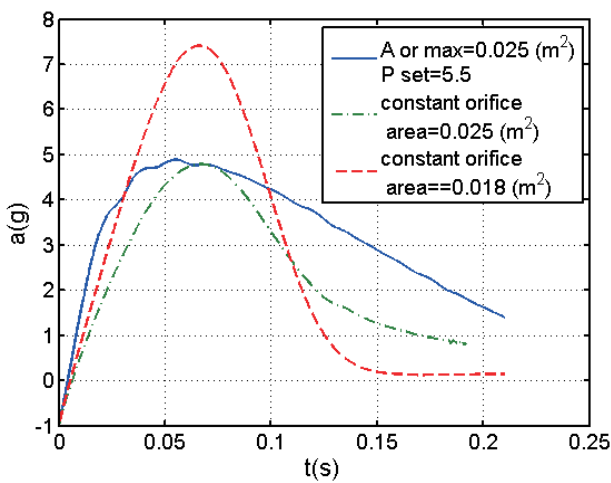

Fig. 11. Acceleration response to compression fixed area orifice with pressure relief valve performance in airbag.

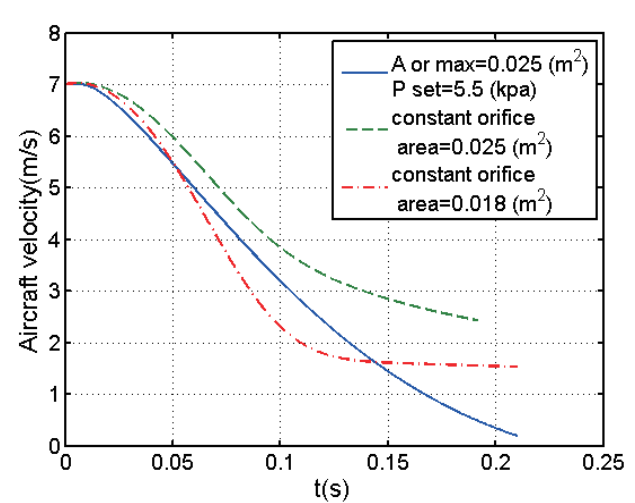

Fig. 12. Velocity response to compression fixed area orifice with pressure relief valve performance in airbag. 
Thus, kinetic energy is absorbed throughout the whole time.

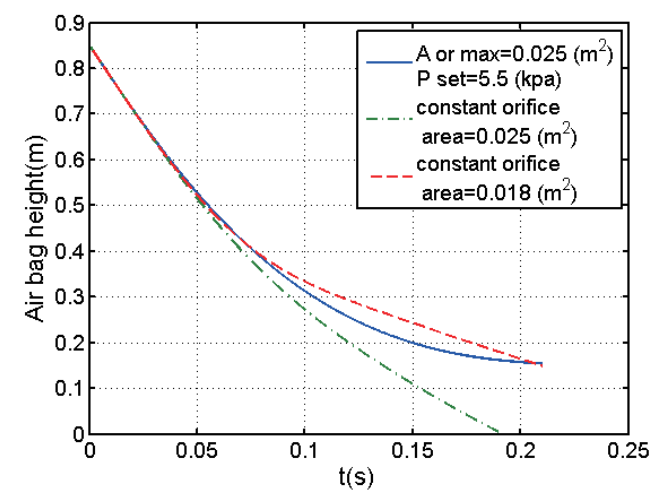

Fig. 13. Airbag h eight response to compression fixed area orifice with pressure relief valve performance in airbag.

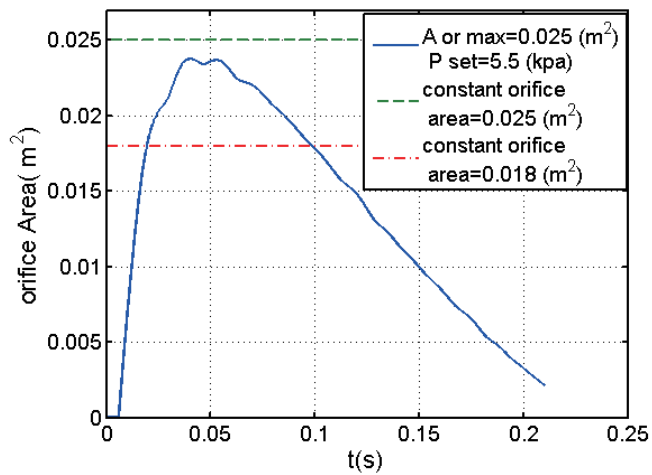

Fig. 14. Orifice area response to compression fixed area orifice with pressure relief valve performance in airbag.

\subsubsection{Optimization of the pressure relief valve}

In this section, the effect of a pressure relief valve on the five airbag types was investigated and using trial and error, $\mathrm{A}_{\text {or max }}$ and Pset were obtained and results are given in Table 2.

In the truncated pyramid airbags, case 1 showed better performance than cases 2 and 3. As seen in Fig. 15 and 16, case 1 has lower maximum magnitude acceleration and pressure. Thus, in the truncated pyramid airbags, case 1 was chosen as the best option. Also, the maximum magnitude of acceleration in the semi-cylindrical airbag was smaller than with the cylindrical airbag, but the maximum airbag pressure in the semi-cylindrical airbag was much larger than the cylindrical airbag. Thus, between the semi-cylindrical and cylindrical airbags, the cylindrical airbag is the best option.

Between the cylindrical (case 4) and truncated pyramid airbag (case 1), when airbag pressure is critical, case 4 is chosen but when payload acceleration is critical, case 1 is the best option.

According to Fig. 17, the end process velocity in all airbag types approaches $0 \mathrm{~m} / \mathrm{s}$. Also, as seen in Fig. 18, cases 13 are useless because of the existing $\mathrm{P}_{\text {set }}$ being $\sim 20 \%$ of the airbag height. Because $A_{\text {or max }}$ is high in cases 4 and 5, the airbag height becomes $0 \mathrm{~m}$ before reaching $\mathrm{P}_{\text {set }}$.

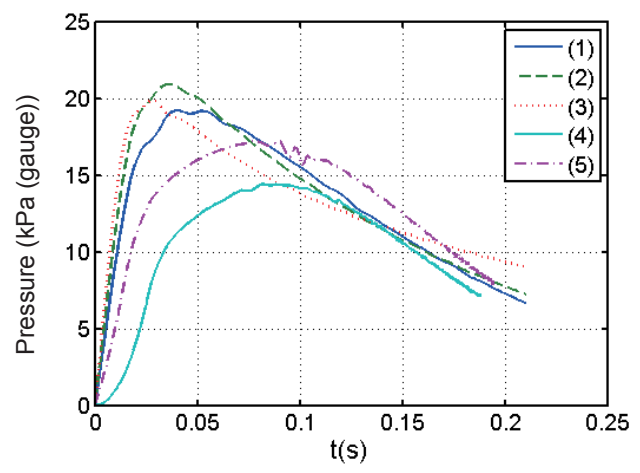

Fig. 15. Pressure response when pressure relief valve is used in airbag.

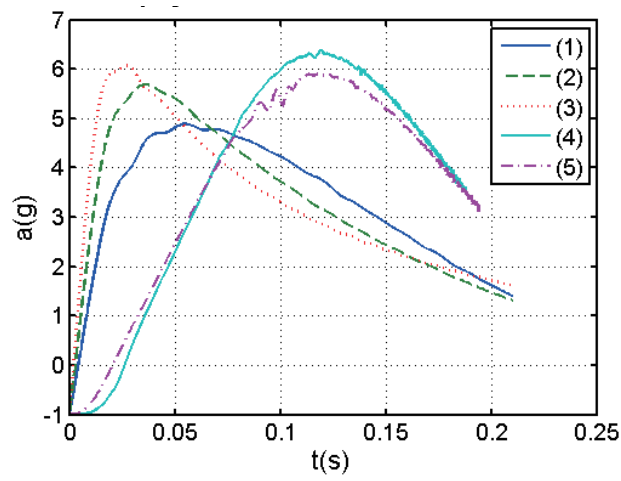

Fig. 16. Acceleration response when pressure relief valve is used in airbag.

Table 2. Specifications for five airbags with different shapes

\begin{tabular}{|c|c|c|c|c|}
\hline $\begin{array}{r}\text { Case } \\
\text { (Airbag }\end{array}$ & $\begin{array}{l}\text { number } \\
\text { Identifier) }\end{array}$ & Airbag type & $\begin{array}{l}\text { Maximum orifice } \\
\text { area }\left(\mathrm{m}^{2}\right)\end{array}$ & $\begin{array}{l}\mathrm{P}_{\text {set }} \\
(\mathrm{kPa})\end{array}$ \\
\hline & 1 & $\begin{array}{l}\text { Truncated pyramid with top } \\
\text { area }=1.5 \times \text { bottom area }\end{array}$ & 0.025 & 5.5 \\
\hline & 2 & Cubic & 0.025 & 6.5 \\
\hline & 3 & $\begin{array}{c}\text { Truncated pyramid with bottom } \\
\text { area }=1.5 \times \text { top area }\end{array}$ & 0.03 & 8.6 \\
\hline & 4 & Cylindrical with $\mathrm{D}=\mathrm{h}$ airbag & 0.041 & 6.9 \\
\hline & 5 & Semi cylindrical with $\mathrm{R}=\mathrm{h}$ airbag & 0.034 & 7.8 \\
\hline
\end{tabular}


Figure 19 shows that the cylindrical airbag (4) has the largest orifice area; thus, the maximum pressure in this leads to lower values compared with the other airbags.

\section{Conclusions}

In this study, five airbags with different shapes were modelled and simulated using different venting systems. For these airbags, under the same working condition, the

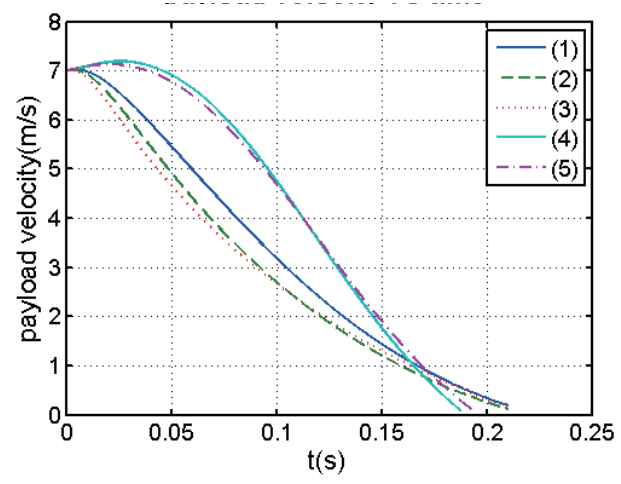

Fig. 17. Velocity response when pressure relief valve is used in airbag.

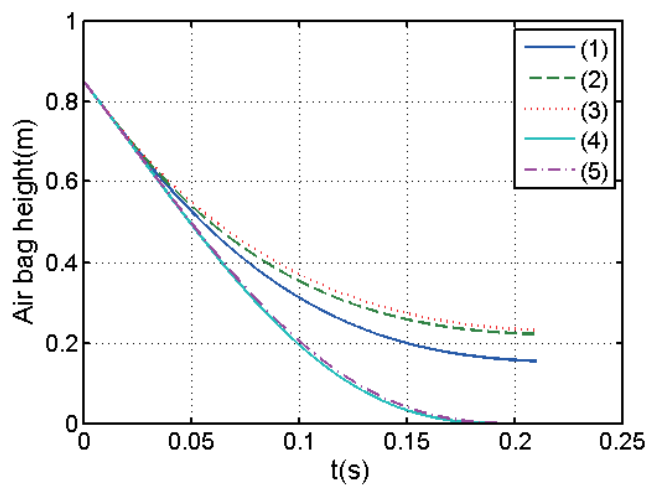

Fig. 18. Velocity response when pressure relief valve is used in airbag.

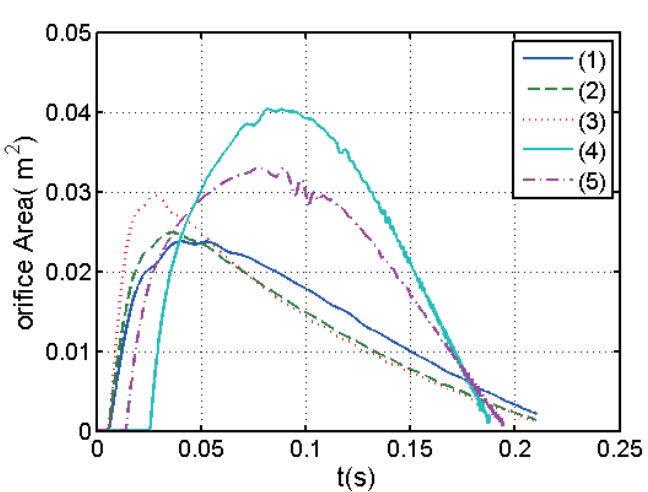

Fig. 19. Orifice area response when pressure relief valve is used in airbag. optimum fixed orifice characteristics with and without a pressure relief valve were calculated. It was shown that the best airbag shape, using a fixed orifice area without a pressure relief valve, was the truncated pyramid airbag, because, this airbag produces the minimum pressure and acceleration responses. Using a pressure relief valve as a venting system, it was observed that the system can be further improved by reducing the maximum pressure and acceleration. Additionally, the pressure relief valve can reduce the end process velocity to about $0 \mathrm{~m} / \mathrm{s}$, meaning the least impact for the UAV's landing. Thus, a pressure relief valve was used in all five airbag models again to investigate the optimum conditions where the maximum pressure and acceleration were reduced to the lowest possible values. By studying the responses of the different airbag shapes using a pressure relief valve, it was shown that the truncated pyramid airbags was still the a better option than the other airbag types. It was also observed that the maximum magnitude of acceleration in the semi-cylindrical airbag was lower than with the widely used cylindrical airbags. However, the maximum airbag pressure in a semi-cylindrical configuration is much higher than with cylindrical shapes. Thus, between semi-cylindrical and cylindrical airbags, a cylindrical airbag is suggested as the better option. Between the cylindrical and truncated pyramid airbags, when the airbag pressure is critical, the cylindrical was chosen but when acceleration is critical, which is the case for UAV safety, the truncated pyramid is suggested as the best option.

\section{References}

[1] Browntng, A. C., A Theoretical Approach to Airbag Shock Absorber Design, her majesty's stationery office, London, 1964.

[2] Rosato, N., Passive airbag vent control valve study, U.S. Army Soldier and Biological Chemical Command Soldier Systems Center Natick, Massachusetts 01760-5017, 1999.

[3] Do, S., Weck, and O.L.d., An Airbag-Based Impact Attenuation System for the Orion Crew Exploration Vehicle, Thesis (S.M.),Massachusetts Institute of Technology, Dept. of Aero-nautics and Astronautics, 2011.,.

[4] Esgar, J. B. and Morgan, W. C., Analytical Study of Soft Landings on Gas-Filled Bags, NASA Technical Report R-75, Lewis Research Center, Cleveland, Ohio. 1960.

[5] Vorticity Ltd, Alternative descent and Landing Technologies, Prepared for European Space Research and Technology Centre, August 2006.

[6] Nelb, G.W., "Global Trends in Airbag Fibers and Fabrics”, International Fiber Journal, Dec 1998.

[7] McGinnis, L., TRW and the airbag industry, Nov. 30, 
1995.

[8] Barnes, J. A. and Rawson, N., "Melt-Through Behaviour of Nylon 6.6 Airbag Fabrics", Proc. Airbag 2000, Fraunhofer Institut für Chemische Technologie, Karlsruhe, 26-27. November, Pub. Fraunhofer press, 1996.

[9] Marlin, B. and Tanov, R., An LS-DYNA User Defined Material Model for Loosely Woven Fabric with NonOrthogonal Varying Weft and Warp Angle, Center for advanced product evaluation, division of IMMI, 2002.

[10] Kellas, S. and Mitcheltree, R., "Energy Absorber Design, Fabrication and Testing for a Pas-sive Earth Entry
Vehicle", 43rd AIAA/ASME/ASCE/AHS/ASC Structures, Structural Dy-namics, and Materials Conference, Denver, Colorado, Apr. 22-25, 2002.

[11] Ross, E. W., Control Systems for Platform Landings Cushioned by Air Bags, Natick Tech-nical Report TR-88/021, U.S. Army Natick Research, Development and Engineering Center, Natick, MA, July 1987.

[12] Lee, C., Rosato, N. and Lai, F., "An Investigation of Improved Airbag Performance by Vent Control and Gasinjection", AIAA PAPER 91-0892, American Institute of Aeronautics and Astronautics, January 1991. 